\title{
(9) UAFF
}

\section{Quantifying the Marine Reservoir Effect for Early Holocene Southeast Alaska}



